\title{
POLÜFUNKTSIONAALNE PIDAMA-VERB XVII SAJANDI KIRJAKEELES ${ }^{1}$
}

\author{
KÜLLI HABICHT, KÜLLI PRILLOP
}

\begin{abstract}
Annotatsioon. Artiklis käsitletakse pidama-verbi leksikaalse ja grammatilise tähenduse vormierinevusi XVII sajandi eesti keeles. Lähenemine on kasutuspõhine ja materjal pärineb vana kirjakeele tekstidest. Selgub, et juba vanima kirjakeele perioodil on pidama-verbi lihtmineviku vormide hulgas sagedasim pidi-vorm kasutusel selgekujulise modaaltähenduste väljendajana. Lähemalt vaadeldakse grammatiliste pidama-konstruktsioonide kasutust XVII sajandi põhjaeesti autorite Heinrich Stahli ja Christoph Blume eesti-saksa rööptekstides, et jälgida pidama-konstruktsioonide 400 aasta tagust grammatiseerumise seisu ja tollaste modaalkonstruktsioonide seoseid. Analüüsil eristatakse dünaamilisi, deontilisi, episteemilisi modaalkonstruktsioone ning lisaks ka deontilise ja episteemilise modaalsuse vahealal paiknevat usutekstidele omast ETTEMÄÄRATUSE tähendust. Postmodaalsetest kategooriatest on selles materjalis esindatud vaid vahendav evidentsiaalsus. Kõige sagedamini esinevad materjalis grammatiseerumise kaudu omavahel seotud ETTEMÄÄRATUSE ja episteemilise VAJALIKKUSE funktsioon. Artiklis tuuakse välja vormi ja funktsiooni seoste põhjal kujunevad kasutusjuhtude rühmad ning hinnatakse saksakeelsetele rööptekstidele tuginedes pidama-konstruktsioonide võimalikku võõrmõjulisust.
\end{abstract}

Võtmesõnad: vana kirjakeel, morfosüntaks, modaalsus, evidentsiaalsus, grammatiseerumine, pidama-verb, eesti keel

\section{Sissejuhatus}

Artiklis võtame vaatluse alla eesti keele ühe keskse (modaal)verbi pidama vormide kasutuse XVII sajandi esimese poole põhjaeesti tekstides. Praeguses kirjakeeles on kaks pidama-verbi, mis vormiliselt eristuvad

${ }^{1}$ Uurimust on toetanud Euroopa Liit Euroopa Regionaalarengu Fondi kaudu (Eestiuuringute Tippkeskus) ning projektid „Eesti vana kirjakeele ressursid“ (EKKM14298), „Eesti keele ajaloo tervikkäsitlus“(EKKM14-345) ja „Kirjakeele morfosüntaksi varieerumise integreeritud mudel: pilootuuring eesti keele näitel“"(PUT 475). 
teineteisest lihtmineviku tunnuse poolest (vt ka Erelt 2001). Leksikaalse tähendusega pidama-verbi 'hoidma; korraldama; hoolima; (midagi millekski) arvama' lihtmineviku tunnuseks on $-s(i)$-, modaalse tähendusega pidama-verbi 'kohustatud olema' puhul aga - $i$-. See erinevus ilmneb ajalooliselt ainult põhjaeesti keeles, kuna lõunaeesti keeles ei kasutata lihtminevikus ühegi sõna puhul analoogiatunnust $-s(i)$-. Artikli üks eesmärk ongi jälgida pidama-verbi vormilist kahestumist põhjaeestilise vana kirjakeele andmetele tuginedes.

Teine eesmärk on avada algsest leksikaalsest tähendusest grammatiseerudes eemaldunud modaalse pidama-verbi konstruktsioonide kasutusvõimalusi XVII sajandi religioossetes tõlketekstides, et selgitada sedakaudu pidama modaaltähenduste kujunemist ning nende omavahelisi seoseid. Ühtlasi jälgime, missuguseid vorme XVII sajandi autorid modaalkonstruktsioonides eelistasid ja kuidas see toetab pidama-verbi vormide eristumist.

Modaalsed pidama-konstruktsioonid on eesti keeles ka enne saksamõjulise vana kirjakeele aega olemas olnud. Sellele osutavad nii vanad rahvalaulud kui ka sugulaskeelte analoogsed konstruktsioonid. Näiteks liivi keeles on netsessiivse tähenduse (KOHUSTUSE) edasiandmiseks kasutusel defektiivsed abiverbid pid̄im ja pid̦iks, mis esinevad koos ma-infinitiiviga nagu eesti keeleski: ma pid̦īm jarā lä'mõ 'ma pean ära minema', sa pid̄iks oppõm 'sa peaks õppima'. Nagu eesti keeles, on ka liivi keeles olemas verb pi'ddõ 'hoidma, pidama', kuid selles on vokaalidevaheline $d$ palataliseerimata, mistõttu ei saa palataliseeritud $d$-ga vorme pid̄im ja pid̄iks pidada $p i^{\prime} d d \tilde{o}$-verbi paradigmasse kuuluvaks ja ka liivi keele puhul tuleb rääkida kahest eri verbist (Viitso 2014: 197-201). Soome keeles on pidama-verbil samuti nii leksikaalne ('hoidma; meeldivust tundma') kui ka grammatiline kasutus. Tõlgendus oleneb sellest, missuguse isiku-, ajavõi kõneviisivormiga on tegu. Ennekõike esineb pidama soome keeles netsessiivkonstruktsioonis, väljendades kohustust, sundust ja sündmuse tõenäosust (episteemiline modaalsus). (ISK 2004: 1497-1500) Konstruktsiooni tüüpilised osalised on genitiivis agent, abiverb pitää ja I infinitiiv (eesti keeles on selle vasteks da-infinitiiv), nt minun pitää mennä 'ma pean minema'. Seega on soome kohustust väljendav konstruktsioon vormilt eesti omast erinev, funktsioonidelt aga osaliselt sarnane. Modaalne pidama-konstruktsioon on olemas ka eesti rahvalauludes, nt Tamm aga kasvis taeva'esse, .. pidi pilved pillutama, kuu pidi lööma kuies tükis 
(ERLA: Lihula. H II 2, 414/5 (546), 1889); See Madli, madala vaimu, võttis see lapse süleje, pidi viskama vedeje (ERLA: Kadrina. H II 55, 815/25 (14) 1896); Jüri tahtis taeva minna, pidi aga põrgusse pugema! (ERLA: Koeru. H II 13, 202 (29), 1888); Jo pidin pea menema, ammu teele astumaie (ERLA: Lüganuse. H IV 4, 29 (10), 1892).

Modaaltähendusterikas usutekstide keel on tinginud pidama-konstruktsioonide osalt saksa keelest mõjutatud lisandumist ja sedakaudu ilmselt ka modaaltähenduste mitmekesistumist eesti keeles. Niisiis oletame, et pidama-verbi spetsiifiliste modaalsete kasutuste puhul on võimalik rääkida kontaktimõjulisest grammatiseerumisest, mida on varem täheldatud nt saama-konstruktsioonides (Metslang 2017; Tragel, Habicht 2017). Peame pidama-verbi kui sagedat, polüseemset ja erinevate grammatiliste kasutustega seotud tuumverbi (vt Tragel 2003) sobivaks indikaatoriks XVII sajandi kirjakeele kasutustava ja morfosüntaksi võõrmõjulisuse hindamisel.

Tähenduste analüüsil keskendume vaid pidama-verbi imperfektivormidele. Just imperfektivormid esindavad tänapäevakeele uurimuste andmetel pidama-verbi kõige kaugemale grammatiseerunud kasutusjuhte (vt Erelt 2001, 2013). Imperfektivormid võimaldavad ka XVII sajandi kirjakeeles leksikaalseid ja grammatilisi kasutusjuhte kõige selgemini eristada ning jälgida, kas autorid kasutavad eri tähenduse ja muutmisviisiga vorme teadlikult ja süsteemselt (vrd ta pidas mind kinni - ta pidi kohe tulema). Vormide lähianalüüsil saab välja selgitada a) autorite vormieelistused kujuneva kirjakeele kasutustava taustal; b) vormi ja funktsiooni seosed ning modaalsete ja postmodaalsete tähenduste kujunemise tagamaad; c) saksa keele tarindite võimaliku eeskuju.

Materjal pärineb eesti vana kirjakeele korpusest (VAKK). Modaaltähenduste lähiuurimiseks on valitud XVII sajandi põhjaeestilise taustaga vaimuliku kirjakeele autorid, kellelt on säilinud eesti-saksa rööptekste (Heinrich Stahl, Christoph Blume). Saksa rööpteksti olemasolu on tähtis kahe keele konstruktsioonide võrdlemiseks ja võimalike saksa mõjude tuvastamiseks. Analüüsimaterjali hulgas on kõik nende autorite tekstides imperfektivormideks märgendatud kasutusjuhud koos lauseümbrustega (Stahlilt 338, Blumelt 16 lausenäidet). Minevikuvormide kasutuse varieerumist vaatleme ka Stahli ja Blume eelsetes tekstides, sest see annab parema ettekujutuse vormivõimaluste kohta enne tugevalt saksamõjulise kirjakeele perioodi. 
Meetod on seega korpuspõhine ning laiemaks teoreetiliseks taustaks on grammatisatsiooniteooria, mis võimaldab kirjeldada modaalsete ja postmodaalsete tähenduste hargnemist konkreetsetest tähendustest abstraktsemate poole (vt Hopper 1991; Hopper, Traugott 1993; Heine 1995; Heine, Kuteva 2002, 2005). Olemuselt on siinne tähenduste analüüs sünkroonne, piirdudes vaid 1630.-1660. aastate juhtude kasutuspõhise varieeruvuse jälgimisega (vt kasutuspõhise meetodi kohta Bybee 2010; Biber 2012). Modaalsete funktsioonide eritlemisel on põhiliseks aluseks Johan van der Auwera ja Vladimir Plungiani modaalsusekäsitlus, mis kirjeldab eri tüüpi modaaltähendusi võIMALIKKUSE ja VAJALIKKUSE skaalal (1998). See käsitlus on eeskujuks olnud ka Mati Erelti modaalsuse liikide kirjeldusele (2013), mida siinses artiklis samuti arvestame.

Eesti keele pidama-tarindeid on varem üsna palju uuritud ja tänapäeval avalduvad modaaltähendused on praeguseks põhjalikult kirjeldatud. Tänapäeva kirjakeele pidama-verbi funktsioone on vaadelnud Mati Erelt (2001, 2013), Ilona Tragel (2003), Pille Penjam (2008). Vana kirjakeele pidama-tarindit on varem käsitlenud Külli Habicht (2001), Laura Merirand (2003), Pille Penjam (2008), Petar Kehayov ja Reeli Torn-Leesik (2009). Kõik need käsitlused on olnud aluseks, millelt siinse täpsemalt piiritletud analüüsi juurde jõuda ning välja selgitada, mida pakub mineviku kirjakeel tänapäevaste kasutusjuhtude selgitamiseks.

\section{Pidama-verbi vormistik vanades põhjaeestikeelsetes tekstides}

Järgmises jaotises kirjeldame pidama-verbi vormistikku kogu säilinud varasema põhjaeesti kirjakeele materjali põhjal kuni XVII sajandi keskpaigani, et vaadelda leksikaalse ja grammatilise pidama-verbi vormistikku eri autorite tekstides ning luua alus vormide ja funktsioonide seoste kirjeldamisele.

\subsection{XVI sajandi tekstid ja Georg Mülleri jutlused}

Kõige varasemates, st XVI sajandist pärit tekstides on pidama-verbi kasutusnäiteid väga vähe, sest sellest ajast ongi säilinud ja VAKKi lisatud vaid 1558 eestikeelset sõnet. Nende väheste näidete põhjal ei saa teha järeldusi pidama-verbi täpsemate tähenduste ega vormistikku mõjutavate faktorite kohta, kuid selgelt ilmneb, et modaalne tähendus 
on juba sel ajal valdav: pidama esineb 26 korral, millest 24 on modaalse tähendusega.

(1) Kuß ux aßi üx kort leppitut on see ep pehe uheste kaiwatut sama. (Liivimaa talurahva õigus, XVI saj keskpaik) ${ }^{2}$

Ka ainus lihtmineviku vorm (kujul piddis) on modaalne.

(2) eth theme Jumalal sel / [Issal] piddis küll tegkeme [medy] [e]ddesth / (Wanradti-Koelli katekismus, 1535)

Georg Mülleri jutlustes (1600-1606) esineb pidama kokku 1607 korral, modaalsena 1388 ja leksikaalses tähenduses 219 korral. Kui jätta arvestamata lühendid, millest ei selgu vormimoodustus, on sagedus vastavalt 1380 ja 216. Ka Müller on kasutanud -is(i)-tunnuselist minevikuvormi piddis, kuid tema tekstides on modaalse tähenduse puhul siiski selgelt ülekaalus tänapäevane pidi-vormiline lihtminevik.

Tabel 1. Minevikuvormide sagedus Mülleri jutlustes

\begin{tabular}{|l|c|c|}
\hline Minevikuvormid & Leksikaalne tähendus & Modaalne tähendus \\
\hline pidi- & - & 108 \\
\hline pidis $(\boldsymbol{i})-$ & 2 & 14 \\
\hline
\end{tabular}

Tänapäeva kirjakeeles on modaalse tähendusega pidama-verb ainus kahesilbiline $a$-tüveline verb, mille lihtmineviku tunnus on $-i$-. Erinevalt $e$-tüvelistest tulema-tüüpi verbidest, mis on säilitanud ajaloolise $i$-tunnuse, peaks pidama olema lihtminevikus $s(i)$-tunnuseline nagu elama, lugema jt ning nagu leksikaalse tähenduse puhul ongi.

Erinevalt tänapäeva kirjakeelest on vanas kirjakeeles $s(i)$-tunnuse ees sageli veel algupärane mineviku tunnus $-i-$. Niisugused vormid olid eelistatud ta-liitelistes verbides, nt leppitis 'lepitas', payetis 'pajatas'; samuti verbides, milles oli võimalik sisekadu, st pika esisilbiga sõnades, mille teine silp oli lühike ja lahtine, nt algkma : algkis 'algama : algas', astma : astis 'astuma : astus', rickma : rickis 'rikkuma : rikkus'. Lühikese esisilbiga sõnades, kus sisekadu ei toimunud, on tavalisemad tänapäevased vormid, kuid ka -is(i-) pole päris võimatu: peale vormi piddis (ka piddisime jne) esinevad tavapäraste vormide ellas, tegki, tulli, panni kõrval harva ka ellis, tegkis, tullis, pannis jm. Et -is(i-) oli kõigis nimetatud verbitüüpides ka

${ }^{2}$ Kõik nummerdatud näited pärinevad VAKKist, sulgudes on lisatud allikas. 
rahvakeeles võimalik, kinnitavad sarnased vormid eesti murretes, nt 'akkis 'hakkas' (saarte murdes), 'kaebis 'kaevas' (läänemurdes), 'kaevis 'kaevas' (läänemurdes), tegis 'tegi' (Mulgi murdes) jm (vt EMK). Et Müller on modaalses tähenduses eelistanud juba tollases keeles muude verbidega võrreldes erandlikku vormi pidi, osutab selle vormi eripärale ja seostumisele grammatilise funktsiooniga juba XVII sajandi alguse keeles. Ajaloolise tunnuse säilimist saaks seletada, kui oletada, et vormi pidi funktsioon on $s$-tunnuse üldistumise ajaks pidama-verbi leksikaalsest tähendusest juba nii palju eristunud, et see vorm oli tajutav omaette grammatilise üksusena ega läinud seetõttu muid sõnu haaranud muutusega kaasa.

Ka olevikuvormide moodustuses võib märgata tähendusest tingitud erinevusi. Pidama on laadivahelduslik tegusõna, mille olevikuvormid tänapäeva keeles on nõrgas astmes tähendusest olenemata. Laadivaheldus kujunes eesti keeles arvatavasti XIV-XVII sajandil. Keeleajalooliselt peaks 3. pööre olema tugevas astmes, kuid toimunud on küllalt hiline astmeüldistus. Näiteks veel 1715. aasta uues testamendis ja 1739. aasta piiblis on nõrgaastmelise vormi peawad kõrval ennekõike leksikaalses tähenduses kasutusel tugevaastmeline piddawad. Huvitaval kombel oleneb nõrga- või tugevaastmelise indikatiivivormi valik Mülleri jutlustes üldjuhul pidama-verbi tähendusest: modaalse tähenduse puhul on ta eelistanud tugevaastmelisi, leksikaalse tähenduse puhul aga nõrgaastmelisi vorme (mitmuse 3. pööre on Mülleril veel eranditult tugevas astmes). Niisugust eelistust saaks ehk seletada lähteparadigmast kaugemale grammatiseerunud modaalse pidiminevikuvormi mõjuga. Konditsionaalis on Müller tähendusest olenemata eelistanud keeleajalooliselt ootuspäraseid nõrgaastmelisi vorme.

Tabel 2. NA/TA varieerumise võimalusega olevikuvormide sagedus Mülleri jutlustes

\begin{tabular}{|l|c|c|c|c|}
\hline \multirow{2}{*}{ Olevikuvormid } & \multicolumn{2}{|c|}{ Leksikaalne tähendus } & \multicolumn{2}{c|}{ Modaalne tähendus } \\
\cline { 2 - 5 } & $\begin{array}{c}\text { Klusiili } \\
\text { kaoga vorme }\end{array}$ & $\begin{array}{c}\text { Klusiiliga } \\
\text { vorme }\end{array}$ & $\begin{array}{c}\text { Klusiili } \\
\text { kaoga vorme }\end{array}$ & $\begin{array}{c}\text { Klusiiliga } \\
\text { vorme }\end{array}$ \\
\hline Sg1, Sg2, P11, P12 & 12 & 1 & 34 & 494 \\
\hline Sg3 & 19 & 8 & 68 & 310 \\
\hline Knd & 3 & 0 & 82 & 3 \\
\hline Neg & 3 & 1 & 17 & 125 \\
\hline ImpSg2 & 7 & 2 & 0 & 5 \\
\hline Kokku & $\mathbf{4 4}$ & $\mathbf{1 2}$ & $\mathbf{2 0 1}$ & $\mathbf{9 3 7}$ \\
\hline
\end{tabular}




\subsection{Heinrich Stahl ja teised XVII sajandi autorid}

Esimene eesti keele sõnaraamat, Heinrich Stahli keeleõpetuse osana ilmunud saksa-eesti sõnastik (1637), esitab verbi pidama kolme saksa verbi vastena; põhitähendusi on siiski kaks nagu tänapäevalgi.

Behalten - piddan, piddasin, piddanut, piddama (Stahl 1637: 40)

Halten - piddan, piddasin, piddanut, piddama (Stahl 1637: 68)

Sollen - pean, peasin $\sim$ piddisin, peanut $\sim$ piddinut, peama $\sim$ piddama (Stahl 1637: 114)

On näha, et ainult modaalverbi sollen 'kohustatud olema' vastena on antud ka nõrgaastmelised vormid, kusjuures Stahl peab nõrgaastmelisena võimalikuks ka $m a$-infinitiivi ja nud-kesksõna. Näib, et juba Stahli jaoks oli pidama-verbi puhul tegemist justkui kahe verbiga, mille muutmisparadigmad on erinevad. Nõrgaastmeline peama on ilmselt Stahli enese teoretiseeringu tulemus. Tema sõnastikus esinevad ka näiteks vormid lugkema : lugken, lugkesin, lugkenut loema : loen, loesin, loenut ja kadduma : kaddun, kaddusin, kaddunut kaoma: kaun, kaosin, kaonut, st ta pidaski laadivahelduslikel sõnadel võimalikuks kahte paralleelset paradigmat. Verbi pidama puhul on ta nende võimalike paradigmadega sidunud ka erinevad tähendused. Leksikaalse tähendusega pidama on alati tugevaastmeline, modaalse tähendusega pidama võib olla nii nõrga- kui ka tugevaastmeline, kuid tugevaastmelistes vormides (v.a $m a$-tegevusnimi) on tüvevokaaliks $-i$.

Stahli teoste tegelik vormikasutus erineb sõnastiku teoretiseeringutest, olles tõenäoliselt tollasele rahvakeelele lähemal. Näiteks ei esine Stahli teostes kordagi $i$-tüvelist $n u d$-kesksõna piddinut, vaid ka modaalses tähenduses on ta kasutanud $a$-tüvelist vormi piddanut (15 korral). Teoretiseeritud vorm peanut pole Stahli teostes üldse kasutust leidnud. Seevastu esineb modaalne peama ka tekstides (8 korral), samas kui piddama puudub täiesti.

Verbi pidama olevikuvormide kasutus Stahli tekstides vastab üsna hästi sõnastikus esitatule: modaalse tähendusega vormid on peaaegu eranditult nõrgaastmelised ja leksikaalse tähendusega vormid tugevaastmelised. 
Tabel 3. Olevikuvormide sagedus Stahli tekstides

\begin{tabular}{|l|c|c|c|c|}
\hline \multirow{2}{*}{ Olevikuvormid } & \multicolumn{2}{|c|}{ Leksikaalne tähendus } & \multicolumn{2}{c|}{ Modaalne tähendus } \\
\cline { 2 - 5 } & $\begin{array}{c}\text { Klusiili } \\
\text { kaoga vorme }\end{array}$ & $\begin{array}{c}\text { Klusiiliga } \\
\text { vorme }\end{array}$ & $\begin{array}{c}\text { Klusiili } \\
\text { kaoga vorme }\end{array}$ & $\begin{array}{c}\text { Klusiiliga } \\
\text { vorme }\end{array}$ \\
\hline Sg1, Sg2, P11, P12 & - & 70 & 1374 & - \\
\hline Sg3 & 4 & 134 & 671 & - \\
\hline P13 & - & 52 & 517 & 5 \\
\hline Knd & - & 1 & 54 & - \\
\hline Imp & - & 97 & - & - \\
\hline Ips & - & 2 & 1 & - \\
\hline Kokku & $\mathbf{4}$ & $\mathbf{3 5 6}$ & $\mathbf{2 6 1 7}$ & $\mathbf{5}$ \\
\hline
\end{tabular}

On huvitav, et Stahli kasutatud olevikuvormide laadivaheldus on täpselt vastupidine tendentsile, mis ilmnes Mülleri jutlustes: Mülleril oli modaalse tähendusega vormides klusiil sagedamini säilinud kui kadunud. Mülleri jutlustes olid ka mitmuse 3. pöörde vormid eranditult tugevas astmes. Tugevaastmelisi mitmuse 3. pöörde vorme leidub veel 1739. aasta piibliski, mistõttu ei saa ainult Stahli teostele tuginedes väita, et astmeüldistus oleviku pöördevormides toimus just XVII sajandi alguses. Tegemist võib olla Stahli sooviga näha vormistikus seaduspärasid, mida seal tegelikkuses veel ei olnud, ja ühtlustada kirjakeele vormistikku. Igal juhul ei ole Stahli tekstid laadivahelduse koha pealt usaldusväärsed ega vasta ilmselt kuigi hästi tollasele tegelikule keelekasutusele.

XVII sajandi rahvakeelele lähemal näib olevat minevikuvormide kasutus Stahli usuteostes. Sõnastikus on si-tunnusega vormid esitatud nii leksikaalse kui ka modaalse tähenduse puhul, $i$-tunnuselist minevikku pole antud. (Tasub märkida, et $i$-tunnusega vormid, nagu surrin ja tullin, on Stahli sõnastikus ja ka tekstides olemas.) Tekstides on aga modaalse funktsiooni puhul sagedasim just pidi-minevikuvorm nagu Mülleri jutlusteski.

Tabel 4. Minevikuvormide sagedus Stahli tekstides

\begin{tabular}{|l|c|c|}
\hline Minevikuvormid & Leksikaalne tähendus & Modaalne tähendus \\
\hline pidi- & 1 & 226 \\
\hline pidis $(\boldsymbol{i})-$ & 5 & 62 \\
\hline peas $(\boldsymbol{i})-$ & - & 50 \\
\hline pidas $(\boldsymbol{i})-$ & 36 & - \\
\hline
\end{tabular}


Mõneti probleemsed on nõrgaastmelised $s$-tunnusega sõnakujud peas, peasin jne, mida võiks pidada ka konditsionaali vormideks, vrd nt läänemurde lõunarühma assimileerunud tunnusega vormid sures, tahas, tees jm (Juhkam, Sepp 2000: 23), kuigi sõnastikus esitab Stahl need minevikuvormidena. Üksikuid sarnaseid $s$-tunnusega vorme, mis oma tähenduselt on pigem konditsionaali vormid, on Stahl kasutanud muudestki verbidest.

(3) Münno Jssa koddas ommat paljo hohnet / kus se mitte ninda ollis / sihs tahasin minna teije wasto ütlema / minna lehn / teile se asseme walmistada. Jn meines Vaters Hauß sind viel Wonungen / wenns nicht so were / so wolt ich zu euch sagen: Jch gehe hin euch die stäte zu bereiten. (Stahl 1638)

(4) OLleme meije hehdt sahnut Jummalalt / ninck ep peasimme sedda kurja mitte kahs wasto wotma. HAben wir guts empfangen von Gott/vnd solten das böse auch nicht annemen? (Stahl 1638)

Konditsionaali ja imperfekti segunemist sakslastest autorite eestikeelsetes tekstides saab peale tunnuste sarnasuse seletada ka saksa keele eeskujuga, kus I konjunktiivi vormid moodustatakse oleviku- ning II konjunktiivi vormid minevikuvormidest. Sealjuures esineb väga palju vormihomonüümiat: indikatiivi olevik võib kokku langeda oleviku konjunktiiviga, nt modaalverbi sollen 'pidama' mitmuse vormid wir sollen, ihr sollet, sie sollen, ja indikatiivi minevik mineviku konjunktiiviga, nt kõik sollen pöördevormid, ich sollte, du solltest jne. Stahli grammatikas (1637) ongi eesti keele konditsionaali paradigma esitatud optatiivina, millele head saksa vastet pole, aga saksa konjunktiivid on eesti keelde tõlgitud tavaliste oleviku- ja minevikuvormide abil. Konjunktiivi tähendust - preesensis eelkõige teostatav soov või oletus, imperfektis ebareaalne tingimus või teostamatu soov - annavad edasi hoopis grammatilised sõnad et ja kus.

Indikatiivi preesens

Indikatiivi imperfekt

Optatiiv

Konjunktiivi preesens

Konjunktiivi imperfekt
Minna sahn, armastan Ich werde, liebe

\section{Minna sain, armastasin} Ich ward, liebete

Eth miña sahxin, armastaxin o das ich doch werde, liebete

Eth minna sahn, armastan da oder dieweil ich werde, liebe

Kus minna ollin, armastasin da oder dieweil ich ward, liebete (Stahl 1637: 14-20) 
Heinrich Gösekeni grammatikas ja sõnastikus (1660) esitatu ei erine milleski olulises Stahli grammatikas kirjeldatust. Christoph Blume tekstides (VAKK: Blume 1662-1667) tulevad aga esile omapärased sisekaolised vormid pidsin, pidsit, pidsime ja pidwat. Indikatiivi olevikuvormides on Blume leksikaalse tähenduse korral eelistanud tugevaastmelist vormi just nagu Stahlgi (kokku 21 esinemust). Erandina on kahel korral kasutatud vorme peap pêep. Modaalse tähendusega olevikuvormid on kõik nõrgas astmes (216 kasutust).

Minevikuvorme on Blume tekstides kokku ainult 18, millest leksikaalse tähendusega vaid kaks, seega tema vormieelistuste üle otsustamiseks on materjali liiga vähe (vt tabel 5). Üks leksikaalse tähendusega vorm on kujul pidi, teine pidsit. Mineviku vormivariant pidi esinebki tal ainult ilma pöördelõputa, alati ainsuse 3. pöördes. Muudes vormides on kasutusel variant pidsi- ja modaalses tähenduses ühe korra erandlikult ka pidasi-. Niisiis näib, et Blume ei lähtunud mineviku vormi valikul mitte tähendusest, vaid vormilistest kriteeriumidest, vt lausenäiteid 5-7.

Tabel 5. Minevikuvormide sagedus Blume tekstides

\begin{tabular}{|l|c|c|}
\hline Minevikuvormid & Leksikaalne tähendus & Modaalne tähendus \\
\hline pidi & 1 & 8 \\
\hline pids $(\boldsymbol{i})-$ & 1 & 7 \\
\hline pidasit & - & 1 \\
\hline
\end{tabular}

(5) Öh kauni könne piddi sehl meij'Jssand Jüngrille Têe pehl

Der HErr hielt' ein freundlich Gespräch mit zween Jüngern auf den Wehg (Blume 1667)

(6) Sedda ütlis Temma aggas se Waimo perrast / kumbat pidsit sahma ke Temma sisse Usksit. Das saget Er aber von dem Geist/welchen empfahen solten di an Jhn gläubeten. (Blume 1662)

(7) Nink lunnastas need / kumbat Surma Kartusse lebbi keike ElloAjal piddasit Sullaset ollema. Und erlösete di / so durch Furcht des Todes / im gantzen Lehben Knechte sein musten. (Blume 1662)

Eelnev vormistiku ülevaade kinnitas hoolimata eri autorite mõningasest varieeruvast kasutusest, et pidi-vorm on spetsialiseerunud modaaltähenduste väljendamisele juba XVII sajandi esimese poole kirjakeeles. 
See osutab grammatiseerunud kasutuse levimisele ja olulisusele vanima kirjakeele perioodil. Vormide ja tähenduste seoseid avame täpsemalt järgmises jaotises.

\section{Modaalne pidama grammatilistes konstruktsioonides}

Siinse jaotise keskmes on Heinrich Stahli ja Christoph Blume tekstides esinevate pidama-verbi vormikujude ja grammatiliste funktsioonide seoste analüüs. Verbi pidama imperfektivormid nende kahe XVII sajandi esimese poole ja keskpaiga olulisima põhjaeesti autori korpusematerjalis pakuvad selleks sobivat ainest. Arvestada tuleb siiski sellega, et autorite materjali hulk on erinev: Stahli tekstides on 321 688, Blumel aga vaid 34912 tekstisõna. Et Blume tekstisõnade hulk on Stahli omast umbes 10 korda väiksem, on tema tekstides tunduvalt vähem ka pidama-konstruktsioone. Umbes 20 korda väiksem pidama-konstruktsioonide hulk Stahliga võrreldes näitab siiski, et Blume tekstides ei olnud pidama-verbi lihtmineviku vormi sisaldavad modaalkonstruktsioonid nii oluline väljendusvahend kui Stahlil. Meenutada tasub ka seda, et vat-tunnuseline kaudne kõneviis ei olnud veel välja kujunenud ja pidama-konstruktsioonidega võidi väljendada ka seda grammatilist tähendust, nt ta piàb pidada aige olema (Kask 1984: 263).

Mati Erelti järgi täidab just imperfektivorm muude modaaltähenduste kõrval ka nt vahendava evidentsiaalsuse (Erelt 2013) ja avertiivi funktsiooni (Erelt 2001). Järgnevalt kirjeldame materjali pidama-verbi imperfektivormide tähendusest lähtudes ning eeldatavat grammatiseerumise suunda järgides. Ülevaate lõpus toome välja grammatiliste tähenduste võimalikud seosed pidama-konstruktsioonide grammatiseerumise ahelas. Rohkem tähelepanu pöörame sagedastele ETTEMÄÄRATUSE ja episteemilise modaalsuse konstruktsioonidele ning nende seostele muude vähem ja rohkem grammatiseerunud konstruktsioonidega.

Stahli ja Blume tekstide korpusematerjalis leidub pidama-verbi imperfektivorme silmatorkavalt erineval määral: Stahlil kokku 338 sellist vormi ning Blumel vaid 16. Infiniitvormi valiku põhjal jagunevad konstruktsioonid järgmiselt. 
Tabel 6. Pidama-konstruktsioonide infiniitvormide sagedus Stahli ja Blume tekstides

\begin{tabular}{|c|c|c|c|}
\hline \multicolumn{2}{|c|}{ Pidama-konstruktsioonid } & Stahl & Blume \\
\hline \multirow{3}{*}{ pidama Ipf +} & $-m a$ & 315 & 13 \\
\hline & $-d a$ & 21 & 3 \\
\hline & - & 2 & - \\
\hline
\end{tabular}

Tabelist 6 on näha, et XVII sajandi esimese poole kirjakeeles võivad pidama-konstruktsioonides varieeruda ka $m a$ - ja $d a$-infinitiiv. Süstemaatiliselt puudutab selline varieerumine vanu ja komplitseeritud muuteparadigmaga verbe tulema, olema, minema ja tegema. Tavaline on siiski $m a$-infinitiiviga konstruktsioon nagu tänapäevalgi. Vormide varieerumist pidama-konstruktsioonis ilmestavad näited, kus olema-verb esineb Stahlil nii $d a$ - (8) kui ka $m a$-infinitiivis (9). Peale eksplitsiitse infinitiivivormiga konstruktsioonide on Stahl kahel korral kasutanud ka väljajättelist pidamakonstruktsiooni, kus ma-infinitiivi vorm on juurdemõeldav (vt näide 11).

(8) Ninck kus meije teije jures ollime / ütlime meije teile enne / Meil piddi willitzuz olla / ninda kudt kahs sündinut on / ninck teije tehte.

Vnd da wir bey euch waren / sagten wirs euch zuvor / wir würden Trübsal haben müssen / wie dann auch geschehen ist / vnd jhr wisset. (Stahl 1638)

(9) Sedda ep olle meile tarwis kartada: Sest kus needt Jüngrit Christum küssisit / mea se lihckpajatus piddi ollema / kostas temma neile:

Dessen haben wir vns nicht zu befaren: Denn / da die Jünger Christum fragten / was diese Gleichnuß were / antwortet er jhnen: (Stahl 1641)

Sellist infiniitvormide varieerumist XVII sajandi tekstides on raske põhjendada. On võimalik, et nende sagedaste verbide puhul oli tegelikus kasutuses veel säilinud kunagine $d a$-infinitiiviline kasutus, nagu on tänapäevani nt soome keeles (hänen pitää tulla).

Järgnevalt anname ülevaate pidama-verbi imperfektivormide funktsioonide jagunemisest Stahli ja Blume tekstides. Et tegu on polüfunktsionaalse verbiga, mis väljendab erinevaid modaaltähendusi, läheneme konstruktsioonidele vormi kõrval ka semantika vaatenurgast ning võtame modaaltähenduste eristamisel arvesse kasutuskonteksti. Funktsioonirühmade sagedusandmed on esitatud kirjeldusele järgnevas jaotises 3.7. 


\subsection{Dünaamiline vaJALIKKUS}

Dünaamilise vajalikkuse funktsioon väljendab agendi võimet ja valmisolekut tegevust sooritada, seega tema sisemist sundi. Selle modaaltähenduse ainsad neli näidet leiduvad Christoph Blume tekstides (näide 10), Stahlil selline kasutus puudus.

(10) Nink mixperrast mitte / armas Hing / mixperrast pidsit nink tachtsit sinna mitte Süddame-Pohjast nink Kihtusse ütlewast Suhst öhe kolmkordalisse Alleluja laskma kuhlma? (Blume 1667)

Tegu on agendikeskse modaalsuse avaldumisega, mis on siin vaadeldud modaalsetest kasutusjuhtudest kõige vähem grammatiseerunud.

\subsection{Deontiline VAJALIKKUS: KOHUSTUS/SUNDUS}

Deontilist vajalikkusmodaalsust esindava KOHUSTUSE näiteid leidub XVII sajandi põhjaeesti tekstides samuti suhteliselt vähe. Ka KOHUSTUS/ SUNDUS on seotud agendile suunatud modaalsusega. Enamjaolt väljendavad pidama-imperfektivormid grammatiseerunumaid modaaltähendusi. KoHustuse tähendust ilmestab järgmine lause.

(11) Se on meile keickelle üx issiehrane röhm / sest / eth meije kül mittekit moistame sest Jummala Waimust / eth meije kül Jummala sisse ni kindlast mitte ussume / kudt meije piddime / tahap temma doch semperrast meid mitte erralückama / erranis oña Pöha Waimo andma / kus meije tem̃a pallume /.. Dies ist vns allen ein sonderbarer Trost / denn / ob wir gleich nichtes vernemmen vom Geist GOttes / ob wir gleich an GOtt so festiglich nicht gläuben / als wir solten / wil er doch darumb vns nicht verstossen / sondern seinen Heiligen Geist geben / so wir jhn bitten .. (Stahl 1641)

SUNDUSE allrühma on paigutatud tugeva KOHUSTUSE näited, kus on tõlgendatav deontilise autoriteedi tugev mõju.

(12) Kus Jacob Mesopotamia Mahst Koddo omma Jssa Mah sisse lex/piddis temma paljo Hedda kannatama / sest temma tagka olli Laban / se hajas temma tagka / ninck tachtis temma huckama / Als Jacob auß Mesopotamia in seine Heymat reisete / muste er viel Gefahr außstehen / denn hinter jhm war Laban / der eilete jhm nach / vñ wolte jhn vmbbringé / (Stahl 1641) 
Selle tähendusrühma edasine grammatiseerumine viib ETTEMÄÄRATUSE modaaltähenduseni.

\subsection{ETTEMÄÄRATUS}

EтTEMÄÄRATUS on usutekstides valdav tähendusrühm (167 esinemisjuhtu), mida esindavad konstruktsioonid väljendavad kõrgema vääramatu autoriteedi tahet, mille teostumine on selle tekstitüübi kirjeldatavas sündmusraamistikus kindel. Selle tähendusrühma võtsime vana kirjakeele materjali kirjeldades kasutusele juba Laura Meriranna bakalaureusetöös (2003) publitseeritud allikates ei ole seda materjali survel esile kerkinud rühma varem nimetatud. ETTEMÄÄRATUSEL on tähenduslik ühisosa KOHUSTUSE/ SUNDUSE rühmaga, kuid see on agentiivsuse nõrgenemise tõttu lähedal episteemilise VAJALIKKUSE tähendusele ning paikneb seega deontilise ja episteemilise modaalsuse üleminekualal. Materjali hulgas ülekaalukalt sagedasim ainsuse 3. pöörde vorm piddi seostubki vanades usutekstides kõige sagedamini just spetsiifilise ETTEMÄÄRATUSE tähendusega.

(13) Ninda on se kirjotut nink ninda piddi CHristus kannatama nink üllestousma surnust kolmandal Pehwal. Also ists geschrieben / und also muste CHristus leiden und aufferstehen von den Toden am dritten Tage. (Blume 1662)

Selline funktsioon on ilmselt arenenud deontilisest modaalsusest, KOHUsTUSE/SUNDUSE tähendusest, ning väljendab sündmuse või olukorra paratamatust piibliteksti endeliste sündmustega määratud kontekstis. Tõlgendus osutab osalejavälisele paratamatule olukorrale, mille tingimused lähtuvad vääramatust autoriteedist ja on ühtlasi järeldatavad üldteada kontekstist.

(14) Mosesse Ajal sait needt Jsraelitit neist tullisest Maddust nohlatut / ninck piddit errasurrema .. Zu Mosis Zeiten wurden die Jsraeliter von den fewrigen Schlangen gebissen / vnd musten des Todes sterben .. (Stahl 1649)

Peale selle on ETTEMÄÄRATUSE modaaltähendusega lauseid sageli võimalik tõlgendada tulevikulisele sündmusele osutavana, st relatiivse tuleviku tähenduses. See seob neid kasutusjuhte tõenäosusmodaalsuse, täpsemalt episteemilise VAJALIKKUSE konstruktsioonidega.

${ }^{3}$ Bakalaureusetöö juhendaja oli Külli Habicht. 
(15) NInck Elisabetti aigk tulli / eth temma piddi omma lapse ilmale kandma / ninck tem̃a kand öhe poja / VNd Elisabeth kam jre zeit / das sie gebären solte / vnd sie gebahr einen Sohn. (Stahl 1638)

\subsection{Episteemiline VAJALIKKUS}

Episteemiliste modaaltähenduste puhul kandub sündmuse toimumise tingimuste üldistus verbiga tähistatud sündmuselt lausesisu tasandile ning lisandub kõneleja/kirjutaja subjektiveeriv hoiak. (Traugott 1989) ETTEMÄÄRATUSEGA on tähenduselt tihedamalt seotud episteemilise VAJALIKKUSE funktsioon, mis on vaadeldud tekstides samuti väga sage (90 esinemisjuhtu; vt näide 16). Seda tüüpi konstruktsioonid väljendavad kõneleja järeldust lausesisu suure tõsikindluse kohta.

(16) Esaias on kuhlutanut / üx wösso piddi üllestöusma Isai puhst / ninck üx ox temma juhrest wilja kandma .. Esaias hat verkündiget / es solte eine Rute auffgehen von dem Stam Isai / vnd ein Zweig ausz seiner würtzel frucht bringen .. (Stahl 1641)

Tüüpiline episteemilise vAJALIKKUSE tähenduse avaldumise ümbrus on siinse materjali põhjal otsustades komplementlause, mis laiendab suhtlusverbe (nt keelama, ütlema, lubama, manitsema, käskima, paluma) või kognitiivverbe (nt mõtlema, arvama, lootma). Sageli on pidama sellistes konstruktsioonides eitavas vormis (näide 17).

(17) Elias üx Innimenne / ninda kudt meije / ninck tem̃a pallus öhe palwe / eth mitte piddi weema saddama .. Elias war ein Mensch / gleich wie wir / vnnd er beht ein Gebet / das es nicht regnen solte .. (Stahl 1641)

Sellisele kasutusele on iseloomulik tõenäosushinnangu konteksti sisaldumine pealauses, pidama-konstruktsiooniga esitatu vahendatus ja tõenäoline teostumine.

Seda tüüpi konstruktsioonide juurest näib grammatiseerumisrada viivat vahendava evidentsiaalsuse funktsiooni juurde (vt joonis 1 ja jaotis 3.6) - sellele osutab konstruktsioonide sarnane ülesehitus, k.a Stahli piddivormide eelistus sellise funktsiooniga konstruktsioonides. 


\subsection{Episteemiline võIMALIKKUS}

Episteemilise võIMALIKKUSE puhul toetab saksa keele eeskuju lausete oletuslikku, tõenäosuslikku tõlgendust. Konteksti põhjal järeldatakse järgnevat sündmust, mille toimumine on võimalik kujutletavas maailmas ega ole seetõttu tõsikindel.

(18) Kus se agkas sünno tachtmisse perrast ninda sündima peas / sihs seisa meije jures / aita meid / eth meije needt tulliset nohlet sest kurjategkijast errakustome .. Da es aber nach deinem Willen also geschehen solte / so stehe vns bey / hilff vns / das wir die fewrige Pfeile des Bösewichtes außlesschen .. (Stahl 1641)

Selle tähenduse edasiandmiseks on Stahl kasutanud eelkõige vormi peas (näide 18). Arvestades Stahli grammatikas esitatut, oli tema tõlgenduses vormiliselt tegu lihtminevikuga, kuigi eesti keele arenguloogikat järgides ei saa tegemist olla muu kui konditsionaaliga (vt 2.2). Stahl on peas-vormi kasutanud ka muudes tähendustes (vt 3.7), kus konditsionaali tõlgendus pole nii ilmne, seega oleme kõik niisugused vormid võtnud oma analüüsi kui lihtmineviku vormid. Nende jõudmine teistesse tähendustesse Stahli tekstides võiski toimuda just episteemilise võIMALIKKUSE tähenduse toel (vt joonis 1). Saksa vaste solte toetab siin samuti mitmetist, nii minevikulist kui ka konjunktiivset analüüsivõimalust.

Pragmaatilistest lausetüüpidest näib ennekõike retooriline küsilause seonduvat episteemilise võIMALIKKUSE väljendamisega.

(19) Eps agkas Jummal peas errapehstma ommat errawallitzetut / kumba pehwa ninck öhdt tem̃a pohle kissendawat? Solt aber GOTT nicht auch retten seine Auszerwehlten/ die zu ihm Tag vnnd Nacht ruffen? (Stahl 1641)

Episteemiline vÕIMALIKKUS ei ole siin käsitletud tekstides nii sage kui episteemiline VAJALIKKUS, kuid esineb siiski nii Stahli kui ka Blume tekstides.

\subsection{Vahendav evidentsiaalsus}

Sündmuse vahendatus on selles funktsioonirühmas ilmsem kui episteemilise VAJALIKKUSE puhul (vrd jaotis 3.4). Lausetes on enamasti olemas eksplitsiitselt väljendatud teate allikas. Saksa vasteks on sellistel juhtudel tavaliselt pidama-verbi I konjunktiivi vorm. 
(20) Selsammal kombel sai kahs Paulus huckatut sest Rahwast Melite sahrest / ke ütlit / temma piddi üx Röhwel olla / kus nemmat negkit Tullest öhe Maddo temma Kehje pehle toußma. Ebener massen ward auch Paulus verdamet von den Leutlin in der Jnsul Melite / welche sagten / er müste ein Mörder seyn / da sie sahen auß dem Fewr eine Otter an seine Hand fahren. (Stahl 1649)

Tänapäeva eesti keeles võiks sellise kasutuse vormiliseks vasteks olla kvotatiiv (-vat). Sarnast vahendavat konteksti ilmestab ka järgmine näide, kus on kasutatud 3. isiku piddis-vormi.

(21) Kus Christus Nicodemusse wasto pajatas / temma piddis uhest sünditut sahma /.. Alsz Christus zu Nicodemo sprach / er muste von newen geboren werden /.. (Stahl 1649)

Näites 21 on näha XVII sajandi tekstidele tüüpilist kolmeosalist verbiahelat (pidi (uuesti) sünnitatud saama), mis kujutab endast läbipõimunud modaalkonstruktsiooni, kus evidentsiaalne pidama-konstruktsioon seob endaga passiivse tulevikukonstruktsiooni saama $+-t u d$.

Vahendava evidentsiaalsuse funktsiooni leidub mõnevõrra vaid Stahli tekstides, kus see pidama-konstruktsioon kuulub tavaliselt refereerivasse kõrvallausesse.

Näidete põhjal võiks järeldada, et pidama-konstruktsioonide kasutamise võimalus kõrvallauses osutab ühtlasi konstruktsiooni kõrgemale grammatiseerumisastmele. Nii on kõrvallauses esinemine omane just episteemilise VAJALIKKUSE ja vahendava evidentsiaalsuse juhtudele, mis ei ole enam seotud agentiivse sündmusega. Järelduslikkuse lisandumine laiemat konteksti arvestades ja sündmuse vahendatus näivad olevat olulised muutuse mehhanismid, mis iseloomustavad pidama-konstruktsioonide grammatiseerumise kõrgemaid astmeid episteemilise modaalsuse vallas.

\section{7. Üldistusi Heinrich Stahli ja Christoph Blume modaalkonstruktsioonide kohta}

Kokkuvõtlikku funktsioonide jaotust Stahli ja Blume tekstides kajastab järgmine loend.

Heinrich Stahli tekstid (1632-1649)

- Deontiline vajalikkus ehk Kohustus/sundus 34

- EtTemä̈̈ratus 159

- $\quad$ Episteemiline vajalikKus 89 
- Episteemiline võimalikKus 39

- Vahendav evidentsiaalsus 17

Christoph Blume tekstid (1662-1667)

- Dünaamiline VAJAlikKus 4

- ETtemä̈̈ratus 8

- Episteemiline võimalikKus 4

Loendist ilmneb, et pidama-imperfektivormide sagedasim kasutusvaldkond on kõrgel grammatiseerumisastmel ETTEMÄÄRATUS ning sellega seotud episteemiline VAJALIKKUS. Stahli tekstides on esindatud ka vahendava evidentsiaalsuse näited. See osutab, et XVII sajandi tekstide tõlkijad kasutasid pidama-verbi lihtmineviku vorme sisaldavaid konstruktsioone usutekstides olulise ETTEMÄÄRATUSE funktsiooni ja lausesisu TÕENÄOSUSE edastamise spetsiifilise grammatilise vahendina.

Eespool käsitletud funktsioonide seostest annab ülevaate järgnev joonis.

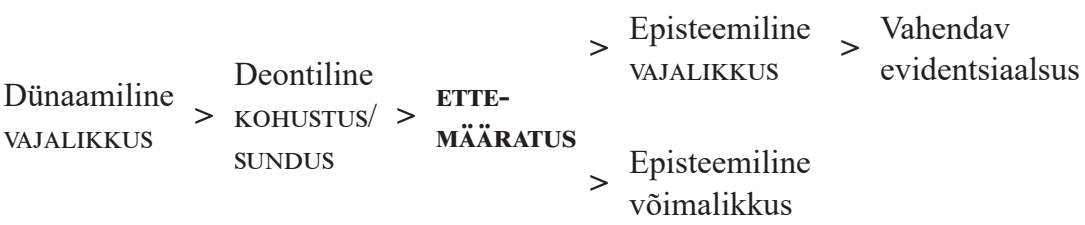

Joonis. Pidama-verbi lihtmineviku vormide grammatiliste tähenduste seosed XVII sajandi põhjaeesti kirjakeele materjali põhjal

Üldjoontes kattub siinne seoste ahel varasemateski töödes kirjeldatuga, kuigi ETTEмÄÄRATUSE funktsiooni olulisust ei ole enne esile toodud. Varasemast täpsemalt on siin eristatud kõrgel grammatiseerumisastmel episteemilise VAJALIKKUSE ja VÕIMALIKKUSE funktsiooni ning on kirjeldatud üleminekuala episteemilise VAJALIKKUSE ja postmodaalse vahendava evidentsiaalsuse funktsiooni vahel. Tänapäeva kirjakeelest leitud avertiivi funktsiooni (Erelt 2001) XVII sajandi esimese poole põhjaeesti usutekstide pidama-imperfektivormidest leida ei õnnestunud. Laura Merirand (2003) on vanema kirjakeele pidama-verbi kasutust uurides Stahli imperfektivormide hulgast küll kolm avertiivi kasutusjuhtu registreerinud, kuid siinses käsitluses on need ületõlgenduse vältimiseks loetud ETTEMÄÄRATUSE näideteks (22). Selget tõlgendusalust nende seostamiseks tähendusega 'sündmus oli peaaegu toimumas, kuid jäi siiski toimumata' ei olnud. 
(22) Eth ep muito kudt surm münno jure jei / porgkohauda piddin minna wahjoma. (Stahl 1641)

Analüüsi tulemusena selgus, et vormi ja funktsiooni seos piddi- ja peasvormide kasutust arvestades ei ole XVII sajandi esimese poole tekstides ühemõtteline, kuigi suundumused on üsna selged. Järgnev loend võtab võimalikud seosed visandlikult kokku. Rohkete piirijuhtumite tõttu kirjeldame siin vaid üldiseid tendentse, mitte täpseid arvandmeid.

Dünaamiline vaJALIKKUS - vaid Blumel, vormid pidsit, pidsin

KoHUSTUS/SUNDUS - piddi- või piddis(i)- (vaid ühel korral peas)

ETTEMÄÄRATUS - piddi- või piddis(i)- (üksikjuhtudel ka peasit)

Episteemiline VAJALIKKUS - valdavalt piddi-, aga ka teised vormid võimalikud Episteemiline võIMALIKKUS - peas- (üksikjuhtudel ka piddi-)

Vahendav evidentsiaalsus - ainult piddi-

Loendist selgub, et KOHUSTUSE/SUNDUSE, ETTEMÄÄRATUSE, episteemilise VAJALIKKUSE ja vahendava evidentsiaalsuse põhiliseks vormivahendiks on tugevaastmeline piddi(si)-. See osutab ühtlasi funktsionaalsele seosele KOHUSTUS/SUNDUS > ETTEMÄÄRATUS > episteemiline VAJALIKKUS > vahendav evidentsiaalsus. Vormilt erinev on harvem esilduva funktsiooni, episteemilise võIMALIKKUSE väljendamine valdavalt nõrgaastmelise vormiga peas-. Sellel vormil võis Stahli tõlgenduses olla seos tingimuslikkuse kategooriaga, mis põhjendab ka selle selgemat funktsionaalset eristamist.

\section{Kokkuvõte}

Uurimuse tulemusena selgus, et pidama-verbi leksikaalne ja modaalne tähendus on eristunud juba XVII sajandi esimese poole tekstides. Eriti puudutab see verbi lihtmineviku vorme ja nende hulgas eriliselt pidi-vormi, mis on kinnistunud selgekujuliseks modaaltähenduse väljendajaks. Seda kinnitasid nii Stahli kui ka Blume tekstide andmed.

Pidama-verbi imperfektivormist ja enamasti $m a$-infinitiivis põhiverbist koosnev konstruktsioon täidab XVII sajandi kirjakeeles mitmesuguseid grammatilisi funktsioone, mis eristuvad peamiselt tähenduse alusel. Tekstiliigi mõjuks võib pidada seda, et pidama-konstruktsioonide kõige esilduvamaks tähendusrühmaks oli ETTEMÄÄrATUS. See tähendus on sillaks deontilise ja episteemilise modaaltähenduse vahel. Vormiliselt on selliseid pidama-konstruktsioone kasutatud saksa konjunktiivivormide vastena ning need väljendavad muu hulgas sageli tegevuse või sündmuse irreaalsust ja 
järelduslikku evidentsiaalsust. Just see funktsioon, mida on toetanud saksa konjunktiivi kategooria, on omane XVII sajandi kirjakeele pidama-imperfektivormidele ja seda võib pidada kontaktimõjulise grammatiseerumise näiteks. Pidama-verbi imperfektivormid esindavad ka muid modaalfunktsioone, nt osalejavälist deontilist võIMALIKKUST, episteemilist VAJALIKKUST ja VÕIMALIKKUST ning postmodaalseks tõlgendatavat vahendavat evidentsiaalsust. Sagedaimad funktsioonid olidki materjalis ETTEMÄÄRATUS ja selle edasiarenduseks tõlgendatav episteemiline vaJALıKKUS. Saksa mõju võib näha vormi ja tõlgenduse sarnases varieerumises (solte - piddi).

Uurimuse tulemuste põhjal võib üldistavalt öelda, et saksamõjulise vana kirjakeele tekstides sagedased grammatilised sõnad (nagu pidama) võimaldavad jälgida modaalkonstruktsioonide grammatiseerumise käiku ning kirjeldada tuumsete ja perifeersete funktsioonide seoseid pankrooniliselt. Nii on võimalik näha järjepidevust tänapäevase ja 400 aasta taguse kirjakeele arengus. Pidama-verbi näitel selgus, et XVII sajandi esimese poole autorid on modaalsete ja postmodaalsete tähenduste väljendamisel kasutanud keeleomaseid konstruktsioone, kuid on neid individuaalselt tõlgendanud. Sagedaste vormikujude analoogial on sel varieeruva ja ebaühtlase kirjakeele perioodil suurem roll kui tänapäeval. Seetõttu tuleb kirjakeele algusaja materjali analüüsides arvesse võtta mõningaid saksaeeskujulisi üldistusi, kuid enamasti pole põhjust alahinnata üldistuste aluseks olnud vormide autentsust, nagu pidi-vormi kasutuse põhjal järeldada võib.

\section{Lühendid}

Imp - käskiv kõneviis; Ipf - lihtminevik; Ips - umbisikuline tegumood; Knd - tingiv kõneviis; NA - astmevahelduslik nõrgaastmeline vorm; Neg - eitav kõneliik; $\mathrm{Pl}$ - mitmus; $\mathrm{Sg}$ - ainsus; TA - astmevahelduslik tugevaastmeline vorm

\section{Kirjandus}

Auwera, Johan van der, Vladimir Plungian 1998. Modality's semantic map. Linguistic Typology 2, 79-124.

Biber, Douglas 2012. Corpus-based and corpus-driven analysis of language variation and use. - Oxford Handbooks Online. http://eclass.uoa.gr/modules/ document/file.php/ (15.10.2016).

Bybee, Joan 2010. Language, Usage and Cognition. Cambridge: Cambridge University Press. http://dx.doi.org/10.1017/CBO9780511750526. 
Erelt, Mati 2001. Some notes on the grammaticalization of the verb pidama in Estonian. - Estonian: Typological Studies V. Ed. Mati Erelt. (= Publications of the Department of Estonian of the University of Tartu 18.) Tartu: University of Tartu, 7-25.

Erelt, Mati 2013. Eesti keele lauseõpetus. Sissejuhatus. Öeldis. (= Tartu Ülikooli eesti keele osakonna preprindid 4.) Tartu.

Göseken, Heinrich 1660. Manuductio ad Linguam Oesthonicam, Anführung Zur Öhstnischen Sprache. Reval, Gedruckt und verlegt von Adolph Simon/ Gymnasij Buchdr.

Habicht, Külli 2001. Eesti vanema kirjakeele leksikaalsest ja morfosüntaktilisest arengust ning Heinrich Stahli keele eripärast selle taustal. (= Dissertationes philologiae estonicae Universitatis Tartuensis 10.) Tartu: Tartu Ülikooli Kirjastus.

Heine, Bernd 1995. Agent-oriented vs. epistemic modality: some observations on German modals. - Modality in Grammar and Discourse. Eds. Joan Bybee, Suzanne Fleischman. (= Typological Studies in Language 32.) Amsterdam: John Benjamins, 17-53. http://dx.doi.org/10.1075/ tsl.32.03hei.

Heine, Bernd, Tania Kuteva 2002. World Lexicon of Grammaticalization. Cambridge: Cambridge University Press. http://dx.doi.org/10.1017/ CBO9780511613463.

Heine, Bernd, Tania Kuteva 2005. Language Contact and Grammatical Change. Cambridge: Cambridge University Press. http://dx.doi.org/10.1017/ CBO9780511614132.

Hopper, Paul J. 1991. On some principles of grammaticalization. - Approaches to Grammaticalization I. Eds. Elizabeth Closs Traugott, Bernd Heine. Amsterdam/Philadelphia: Benjamins, 17-36.

Hopper, Paul J., Elizabeth Closs Traugott 1993. Grammaticalization. Cambridge Textbooks in Linguistics. Cambridge: Cambridge University Press.

ISK = Auli Hakulinen (päätoimittaja), Maria Vilkuna, Riitta Korhonen, Vesa Koivisto, Tarja Riitta Heinonen, Irja Alho 2004. Iso suomen kielioppi. Helsinki: Suomalaisen Kirjallisuuden Seura.

Juhkam, Evi, Aldi Sepp 2000. Läänemurde tekstid. Toim. Anu Haak. (= Eesti murded VIII.) Eesti Keele Instituut. Tallinn: Eesti Keele Sihtasutus.

Kask, Arnold 1984. Eesti murded ja kirjakeel. (= Eesti NSV Teaduste Akadeemia Emakeele Seltsi toimetised 16.) Tallinn: Valgus.

Kehayov, Petar, Reeli Torn-Leesik 2009. Modal verbs in Balto-Finnic. - Modals in the Languages of Europe. A Reference Work. Eds. Björn Hansen, Ferdinand de Haan. (= Empirical Approaches to Language Typology 44.) Berlin, New York: Mouton de Gruyter, 363-401. 
Merirand, Laura 2003. pidama-verbi grammatikaliseerunud kasutusest vanemas kirjakeeles. Bakalaureusetöö. Käsikiri Tartu Ülikooli eesti ja üldkeeleteaduse instituudi raamatukogus.

Metslang, Helle 2017. Can a language be forced? The case of Estonian. - Aspects of Grammaticalization. (Inter)subjectification and Directionality. Eds. Daniel Van Olmen, Hubert Cuyckens, Lobke Ghesquière. (= Trends in Linguistics Studies and Monographs 305.) Berlin/Boston: De Gruyter Mouton, 281-309.

Penjam, Pille 2008. Eesti kirjakeele $d a$ - ja $m a$-infinitiiviga konstruktsioonid. (= Dissertationes philologiae estonicae Universitatis Tartuensis 23.) Tartu: Tartu Ülikooli Kirjastus.

Stahl, Heinrich 2000 (1637). Anführung zu der Esthnischen Sprach/ auff Wolgemeinten Rath/ vnd Bittliches Ersuchen/ publiciret von M. Henrico Stahlen. Revall/ Druckts Chr. Reusner der älter/ in Verlegung des Authoris. (= Maarjamaa taskuraamat 15.) Brampton-Tartu.

Tragel, Ilona 2003. Eesti keele tuumverbid. (= Dissertationes linguisticae Universitatis Tartuensis 3.) Tartu: Tartu Ülikooli Kirjastus.

Tragel, Ilona, Külli Habicht 2017. Saama-verb grammatilistes konstruktsioonides. - Keel ja Kirjandus 1, 22-40.

Traugott, Elizabeth Closs 1989. On the rise of epistemic meanings in English: an example of subjectification in semantic change. - Language 57, 33-65.

Viitso, Tiit-Rein 2014. Expressions of obligation, duty, and necessity in Livonian. - Eesti ja soome-ugri keeleteaduse ajakiri 5 (1). Special issue: Studies on Livonian, 193-214. http://dx.doi.org/10.12697/jeful.2014.5.1.10.

\section{Korpused}

EMK = Eesti murrete korpus. http://www.murre.ut.ee/murdekorpus/.

ERLA = Eesti regilaulude andmebaas. Eesti Kirjandusmuuseumi Eesti Rahvaluule Arhiiv. http://www.folklore.ee/regilaul/andmebaas.

VAKK = Tartu Ülikooli vana kirjakeele korpus. http://www.murre.ut.ee/vakkur/ Korpused. 


\title{
The multifunctional verb pidama in 17th-century written Estonian
}

\author{
KÜLLI HABICHT, KÜLLI PRILLOP
}

The article deals with differences in form between the lexical and grammatical meanings of the verb pidama 'keep; consider; must, have to' in 17th-century Estonian. Our approach is usage-based, relying on material from the Corpus of Old Written Estonian. We focus on the usage of past tense forms of the polysemous verb pidama in 17th-century North Estonian texts. The aim is to explain the background of the divergence in form between the two meanings of pidama in use today, as well as the relationships between its modal meanings. We assume that the influential translated religious texts of the 17th century created a tradition of usage of frequently occurring morphosyntactic constructions, wherein the choice of form emerged from the vernacular.

The analysis reveals that the lexical and modal meanings of pidama were distinguished as early as in the first half of the 17 th century. This especially concerns the simple past tense forms of the verb, in particular the form pidi, which has become clearly associated with modal meanings.

The construction consisting of the past tense form of pidama and a main verb typically in the $m a$-infinitive (a.k.a. supine) form performed different grammatical functions in 17th-century written Estonian. An influence of the text type can be seen in that the most common meaning associated with pidama constructions was PREDETERMINATION. This meaning is also a bridging context between deontic (OBLIGATION/COMPULSION) and epistemic modal meanings. The epistemic usage, typical of past tense forms of pidama in the 17th-century written language, has been supported both in meaning and in form by the German subjunctive, which indicates contact-driven grammaticalization.

The past tense forms of the verb pidama indicate, in addition to the most frequent PREDETERMINATION, also participant-external deontic POSSIBILITY, epistemic NECESSITY and POSSIBILITY, and indirect evidentiality, which can be regarded as a post-modal meaning. The study reveals that the writers of the first half of the 17th century used authentic constructions to express modal and post-modal meanings, but gave their individual interpretations to these constructions.

Keywords: Old Written Estonian, morphosyntax, modality, evidentiality, grammaticalization, verb pidama, Estonian language 


\section{Külli Habicht}

eesti ja üldkeeleteaduse instituut Tartu Ülikool

Jakobi 2

51014 Tartu

kulli.habicht@ut.ee

Külli Prillop

eesti ja üldkeeleteaduse instituut Tartu Ülikool

Jakobi 2

51014 Tartu

kulli.prillop@ut.ee 